\title{
Influence of Material Condition on the Dry Sliding Wear Behavior of Spring Steels
}

\author{
K. V. Arun* and K.V. Swetha
}

\section{ABSTRACT}

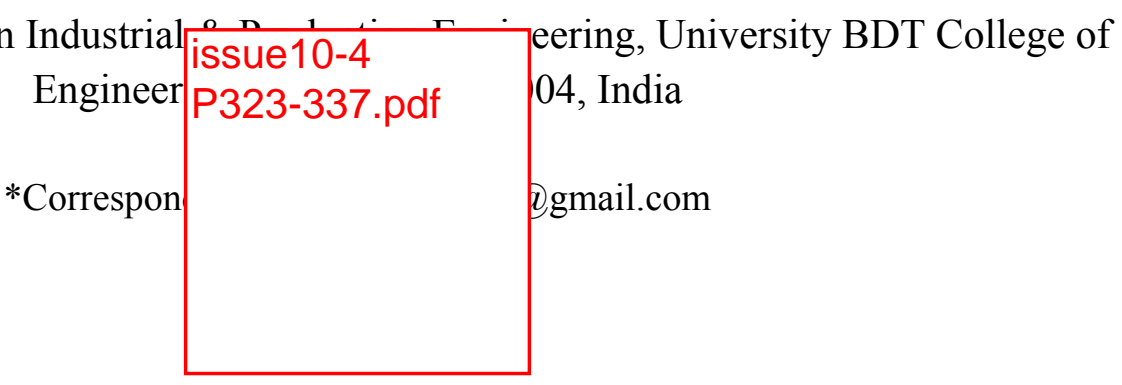

During the past two decades, considerable efforts have been made in the development of high performance spring steels to meet the needs for weight and savings in the automotive industry. During the service the suspension system will be subjected to different environmental conditions, at the same time it has to sustain a variety of loads acting on it. Among all the wear of spring steel plays a vital role. In this experimental analysis an attempt has been made to investigate the performance of spring steel (EN-47 / SUP 10) under the dry sliding condition. The specimen preparation and the experimentations have been carried out according to the ASTM G99 standards. The effects of tempering and cryogenic treatments on the performance of the spring steel have also been determined. The results have revealed that the material condition has got a significant influence on the performance of the spring steel. In order to analyze the percentage contribution of different wear parameter and the material condition, the DOE and ANOVA have been made. The results have shown that the load (49.205\%) has shown the highest influence and the material condition has shown $22.56 \%$ of contribution on wear behavior.

Key Words: Dry Sliding Wear, Tempering, Cryogenic Treatment, ANOVA, Wear Loss.

\section{INTRODUCTION}

Aggressive mass reduction trends in the automotive industry have spurred the development of suspension springs that can withstand high stresses at a reduced section size [1]. Major applications of spring steel are in Railway coach axles, Crank pin on heavy machines, Crank shafts, Spline Shafts, leaf spring likewise. New trends in development of automotive industry can be formulated as follows: higher passenger's safety, fuel consumption decrease and higher 
comfort with better furnishing. During the last two decades, considerable efforts have been made in the development of high-performance spring steels to meet the needs for the weight and cost savings in the automotive industry [2].

Different heat treatment processes can be applied on the spring element of a force transducer in order to obtain good and satisfactory performance. The manufacturers are generally focused on the improvement of performance by applying different heat treatments on spring material [3]. Today, most coil springs for automotive applications are made of quenched and tempered, medium carbon high-strength steels. In order to increase the harden ability of elements such as chromium, manganese and silicon are added to these steels [4]. The primary objective of the heat treatment of steels is to improve wear resistance. The benefit of cryotreatment of steels has been cited by several researchers. However, the mechanisms responsible for enhancing the wear resistance by cryotreatment are yet to be clearly established. Recent work has also shed light on the effects of cryogenic treatment on bearings, gears and engine components to reduce wear and improve performance [5-6].

Spring steels are used in the quenched and tempered condition which gives optimum strength and toughness, vibrational damping. The change in microstructure and strength after the heat treatment process depends on the cooling rate obtained during quenching [7]. Due to operational safety, springs have to meet increasing performance requirements, which concern mechanical properties, tribological properties as well as fatigue strength [8].

The improvement of the sag resistance has been achieved by changing prior austenite grain size, the distribution of precipitated particles, and the chemical composition of the steel, as well as by changing processing treatments such as magnitude of pre-strain and shot-peening [9]. Some mechanical properties such as elastic modulus, tensile strength, hardness, microstructure, strain hardening and fracture strain also influence the wear of the materials. Hardness is a measure of the wear resistance of a material. In other words it is the resistance of a material to permanent deformation by indentation or scratching [10]. Hardness of material depends upon the type of bonding forces between atoms, ions or molecules. Furthermore for spring steels, the emphasis in materials research has been focused on increasing the strength while maintaining good ductility, toughness and fatigue properties [11].

Prevention of wear depends principally on design and operation of component, but can be minimized by the correct choice of material. It is seen that most of the study has been focused on the experimental work for wear behavior of steels, and a few mathematical models based on statistical regression techniques has been reported[12-15]. The Taguchi's design is a simple, efficient and systematic approach to optimize designs for performance, quality and cost [16]. In the Taguchi method, Design of experiments approach enables to analyze successfully the wear behavior of materials [17]. The design of an experiment (DOE) technique is a optimized 
technique mainly employed in determining wear behavior of material, which must follow certain sequence for the experiments to yield an improved understanding of product or process performance [18].

From the literature survey it is clear that there is lot of scope for the study of wear behavior of spring steel. Hence present study was focused on the dry sliding wear behavior of spring steel and the effect of heat treatment on spring steel. The main aim was to investigate the effect of applied load, sliding distance, sliding speed and material conditions which mainly influences the dry sliding wear of the spring steel with the help of Taguchi technique under various testing conditions. Furthermore, the analysis of variance (ANOVA) is employed to investigate the testing characteristics of different steels. Tests were carried out using a pin-on-disc type of apparatus under different conditions. A major step in the DOE process is the determination of the combination of factors and levels which will provide the experimenter with the desired information.

\section{MATERIAL AND EXPERIMENTATION}

The experimentation has been carried out on spring steel material EN-47 (SAE 6150 Steel). The specimen preparation and experimentation were carried out according to ASTM standards. The mechanical properties of EN-47 spring steel material has a hardness of 99 HRC, yield strength of $640 \mathrm{Mpa}$, density of $7.85 \mathrm{~g} / \mathrm{cc}$ and modulus of elasticity $205 \mathrm{Gpa}$. The chemical composition of the materials used in the investigation is as follows.

Table 1 Chemical composition of EN 47

\begin{tabular}{cccccc}
\hline Components & $\mathrm{C}$ & $\mathrm{Mn}$ & $\mathrm{Si}$ & $\mathrm{Cr}$ & $\mathrm{V}$ \\
\hline $\mathrm{Wt} \%$ & $0.48-0.53$ & $0.70-0.90$ & $0.20-0.35$ & $0.80-1.10$ & $0.15-0.25$ \\
\hline
\end{tabular}

\subsection{Material Condition}

The specimens were tested under different conditions to analyze the influence of each condition of the material fracture characterizing parameters. The conditions of the material are, Normal, Tempered at $250^{\circ} \mathrm{C}$ and $350^{\circ} \mathrm{C}$ and Cryogenic.

Specimens are kept under procured condition and tested to evaluate characterizing parameters like hardness and wear under normal condition. The specimens are heated to annealing temperature $\left(700^{\circ} \mathrm{C}\right)$ and are cooled by oil quenching. Then these specimens are tempered at $250^{\circ} \mathrm{C}$ and $350^{\circ} \mathrm{C}$. The process of heat treatment for tempering is shown in Figure 1. Since the specimens are annealed and quenched the quench cracks are developed in the specimens. These quench cracks gets healed up after tempering at different tempering temperatures such as $250^{\circ} \mathrm{C}$ and $350^{\circ} \mathrm{C}$. 


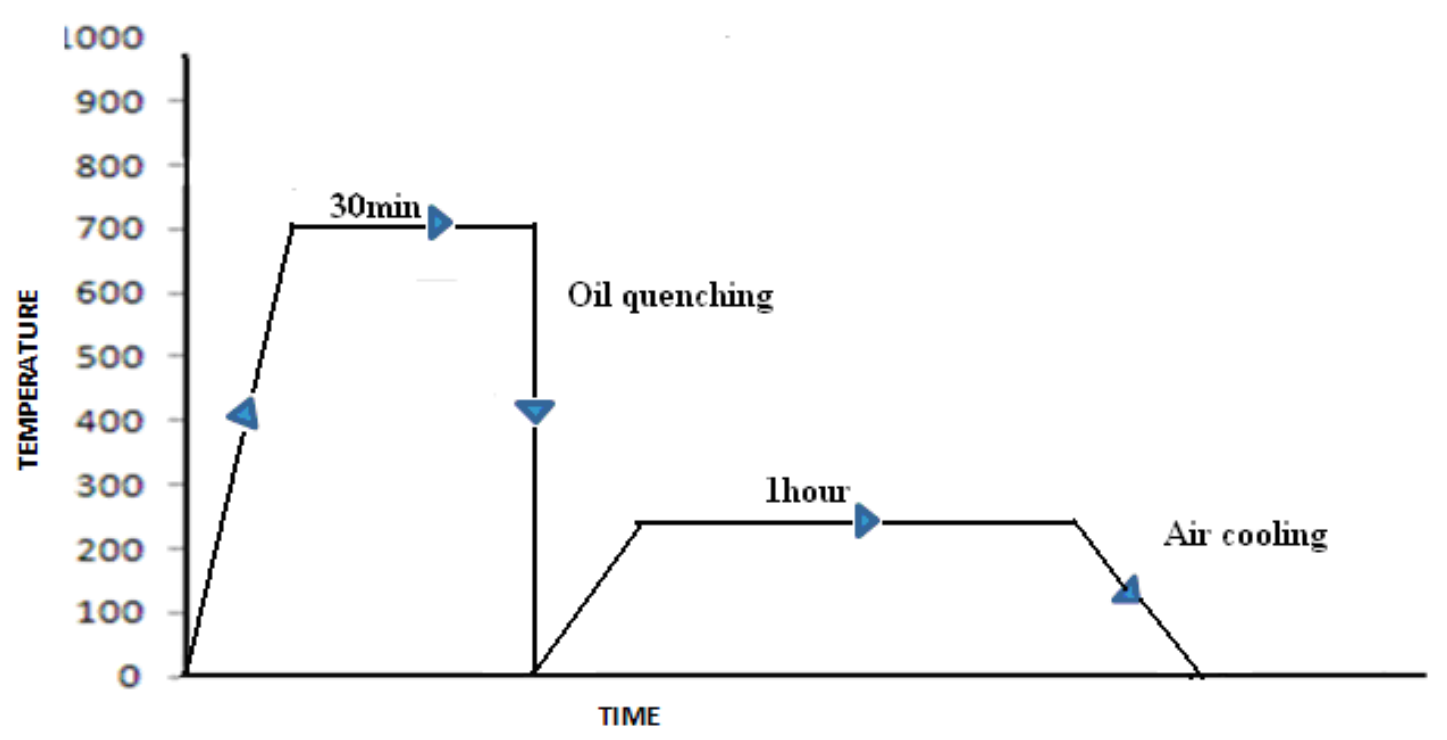

Figure 1 Heat treatment Cycle for Tempering

Instead of tempering, the specimens are kept under cryogenic condition as shown in Figure 2. The quench crack developed during annealing will increase further after cryogenic treatment.

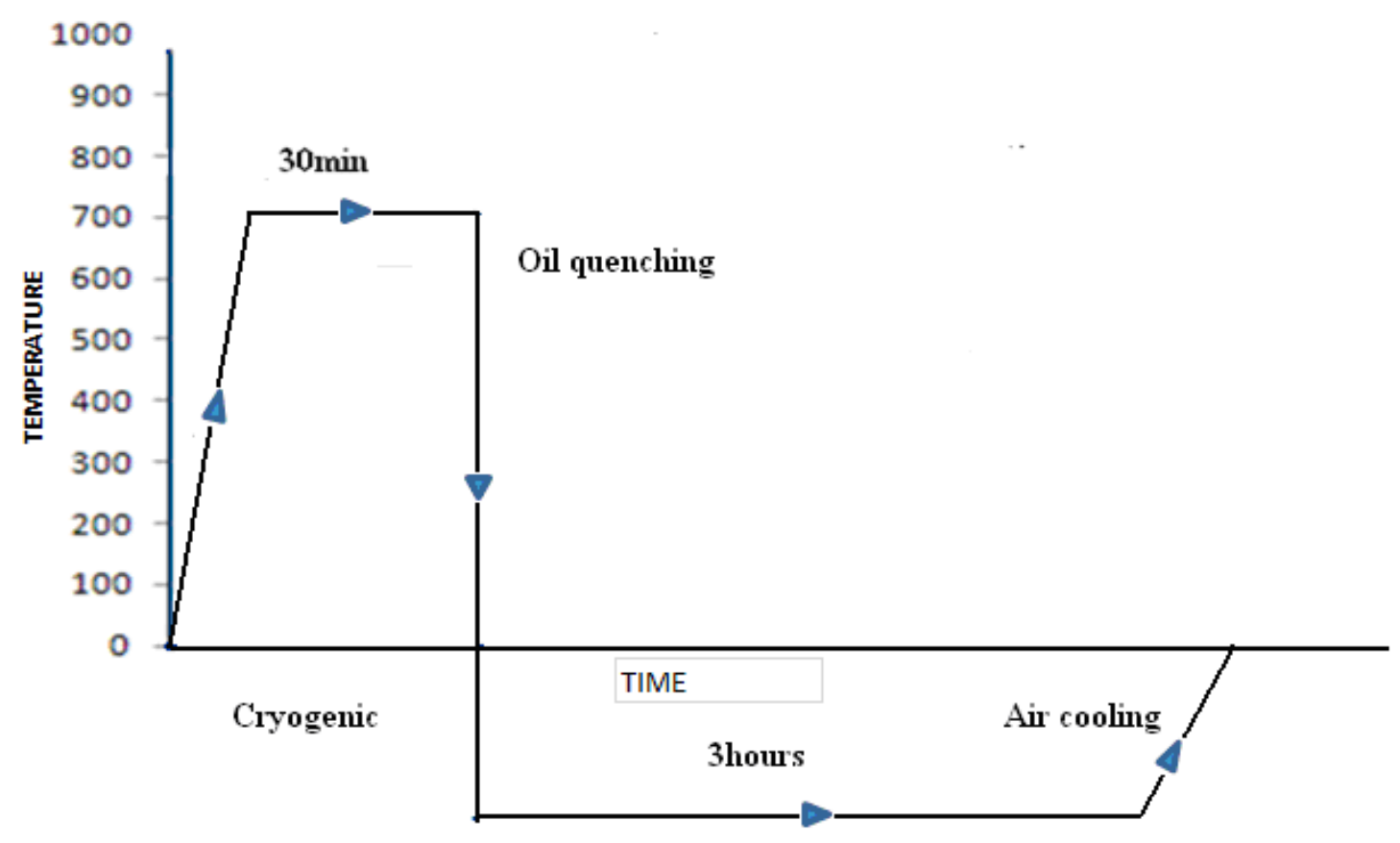

Figure 2 Cycle of Cryogenic Treatment 


\subsection{Experimentation}

The experimentations were carried out in order to determine the wear property of the spring steel. A pin-on-disc test apparatus was used to investigate the dry sliding wear characteristics of the spring steel (EN-47) material as per ASTM standards. The disc used is En-32 steel hardened to $62 \mathrm{HRC}, 135 \mathrm{~mm}$ track diameter and $8 \mathrm{~mm}$ thick, with surface roughness of $10 \mu \mathrm{m} \mathrm{Ra}$. Specimens are prepared from the standard bar of $12 \mathrm{~mm}$ diameter and turned to $10 \mathrm{~mm}$ diameter and are cut to $25 \mathrm{~mm}$ length. The tests were conducted by selecting test duration, load and velocity and performed in a track of $115 \mathrm{~mm}$ diameter. The specimen prepared are positioned parallel using die holder and in same sliding direction. The test set up used for the experimentation is as shown in the Figure 3. The difference in the weight measured before and after test gives the sliding wear of spring steel specimen and then the volume loss was calculated.

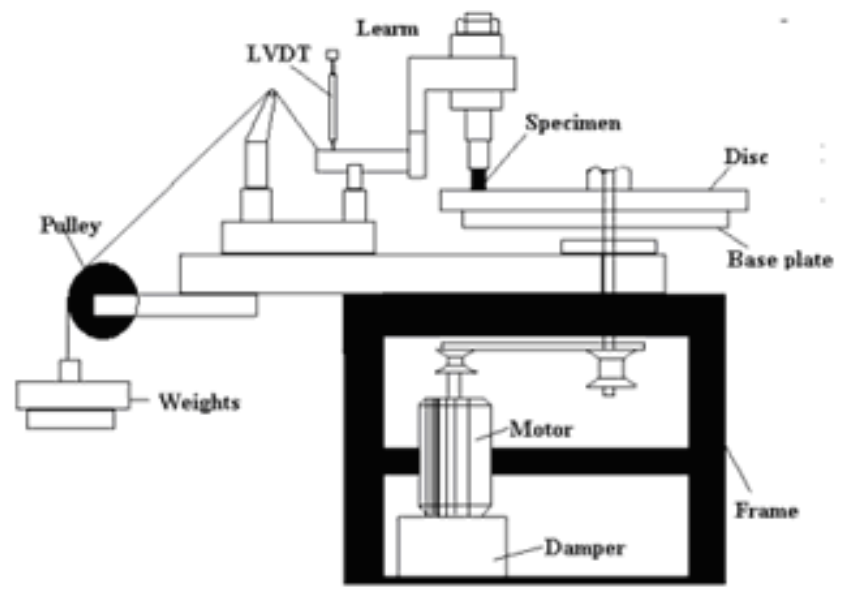

Figure 3 Schematic Diagram of Pin on Disk Apparatus

\subsection{Design of Experiments}

The Taguchi approach to experimentation provides an orderly way to collect, analyze, and interpret data to satisfy the objectives of the study. This design can optimize the performance characteristics through the setting of design parameters and reduce the sensitivity of the system performance to the source of variation. This technique is a powerful tool for acquiring the data in a controlled way and to analyze the influence of process variable over some specific variable, which is unknown function of these process variables. The most important stage in the plan of experiments is selection of factors. Taguchi technique creates a standard orthogonal array to accommodate the effect of several factors on the target value and defines the plan of experiments. The experimental results are analyzed using analysis of means and variance to 
study the influence of factors. The Experiments were conducted as per the standard orthogonal array so as to investigate which design parameter significantly affects the dry sliding wear for the selected combinations of load, sliding speed and sliding distance and material. The selection of the orthogonal array was based on the condition that the degree of freedom for the orthogonal array should be greater than or equal to sum of those wear parameters. In the present investigation an $\mathrm{L}_{9}$ orthogonal array was chosen, this has 9 rows and 4 columns as shown in the Table 2.

Table $2 \mathrm{~L}_{9}$ Orthogonal Array

\begin{tabular}{ccccc}
\hline Trial no. & A & B & C & D \\
\hline 1 & 1 & 1 & 1 & 1 \\
2 & 1 & 2 & 2 & 2 \\
3 & 1 & 3 & 3 & 3 \\
4 & 2 & 1 & 2 & 3 \\
5 & 2 & 2 & 3 & 1 \\
6 & 2 & 3 & 1 & 2 \\
7 & 3 & 1 & 3 & 2 \\
8 & 3 & 2 & 1 & 3 \\
9 & 3 & 3 & 2 & 1 \\
\hline
\end{tabular}

Table 3 Process parameters and their levels

\begin{tabular}{ccccc}
\hline Levels & Load $(\mathrm{N})$ & Speed (rpm) & $\begin{array}{c}\text { Sliding } \\
\text { distance }(\mathrm{m})\end{array}$ & $\begin{array}{c}\text { Material } \\
\text { conditions }\end{array}$ \\
\hline 1 & 7 & 900 & 5000 & $350^{0} \mathrm{C}$ \\
2 & 5 & 700 & 3000 & $250^{\circ} \mathrm{C}$ \\
3 & 3 & 500 & 1000 & $27^{\circ} \mathrm{C}$ \\
\hline
\end{tabular}

The wear parameters chosen were (1) sliding speed (2) Load (3) sliding distance (4) material and their levels indicated in table 3. The experiments consist of 9 tests (each row in the L 9 orthogonal array) and first column in table was assigned to load (L), second column was assigned to sliding speed (S), third column was assigned to sliding distance (D) and fourth column was assigned to material. 


\section{RESULTS AND DISCUSSIONS}

The spring steel is characterized for its strength assessment. The experimentations were carried out to determine the most significant parameters which influence on the wear behavior of the springs in service. The results of the experimentation have been summarized and discussed in section.

\subsection{Hardness Test}

The hardness trials were taken at different regions of the specimen and the average value of which is tabulated. Rockwell $\mathrm{C}$ hardness test is used to determine the hardness. The hardness of material at different conditions is tabulated in Table 4. The maximum Hardness is obtained in the cryogenic material (61.5 RHN.). The minimum Hardness obtained in normal untreated specimens (26 RHN.). Due to the change in the structure of the material, the hardness has increased. Since the cryogenic treatment has been done after quenching, the quench cracks get widened further. This leads for increased hardness.

Table 4 Hardness of Spring Steel in Different Conditions

\begin{tabular}{lcccc}
\hline \multicolumn{1}{c}{ SPECIMEN } & RHN-B & RHN-C & BHN & VHN \\
\hline $\begin{array}{l}\text { Normal } \\
250^{\circ} \mathrm{C}\end{array}$ & 98.6 & 26 & 258 & 272 \\
Tempered & 129 & 45 & 421 & 446 \\
$350^{\circ} \mathrm{C}$ & 124 & 51 & 487 & 528 \\
Tempered & 110.5 & 61.5 & 688 & 746 \\
Cryogenic & & & & \\
\hline
\end{tabular}

\subsection{Influence of Sliding Distance on the Wear Behavior}

Wear behavior of spring steel plotted as a function of sliding distance is shown in Figure 4. This represents the variation of wear rate with sliding distance at a constant load of $5 \mathrm{~kg}$ and speed 700 rpm for different material conditions like normal, $250^{\circ} \mathrm{C}, 350^{\circ} \mathrm{C}$ and cryogenic conditions. The weight loss increased with increasing sliding distance for all condition. The wear rate increases continuously in normal specimens. The wear is increasing gradually upto $3000 \mathrm{~m}$ distance beyond that wear is increased rapidly in $350^{\circ} \mathrm{C}$ heat treated specimens and in $250^{\circ} \mathrm{C}$ heat treated specimens the wear is increasing with respect to distance. Theoretically cryogenic treated 
specimen must have less wear rate compared to normal specimen because of high hardness. Even though it is showing high wear rate upto $3000 \mathrm{~m}$ due to the crack widening in cryogenic treated specimen, above $3000 \mathrm{~m}$ the wear rate becomes stable because of formation of smeared layer which heals the cracks. Finally from the distance $4000 \mathrm{~m}$ to $5000 \mathrm{~m}$ the wear rate gets increased but less than normal specimen this is because the specimen reached unstable condition where the smeared layer gets peeled off at that distance.

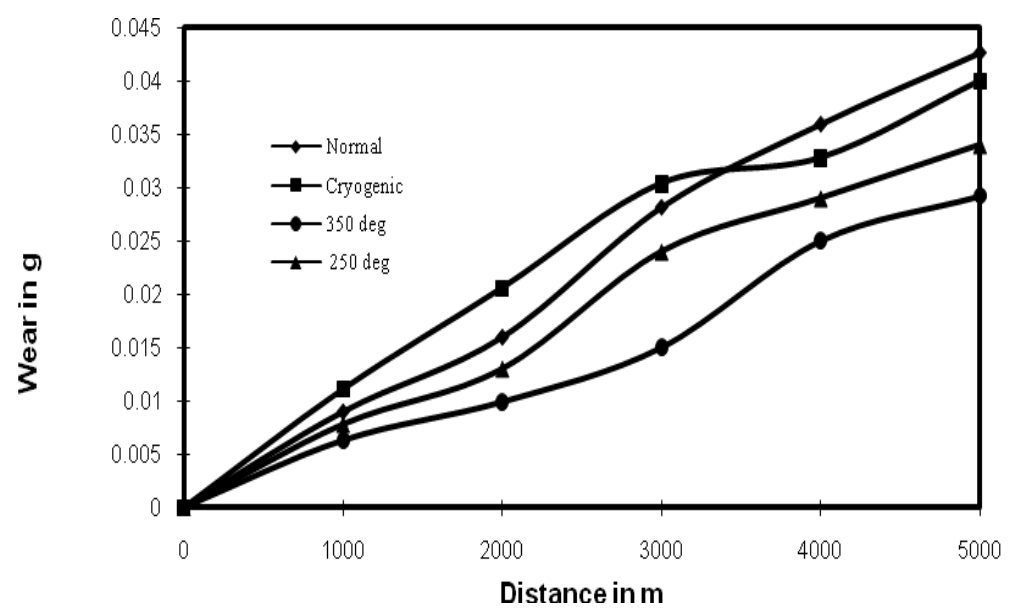

Figure 4 Shows Variations of Wear Rate of Spring Steel with Sliding Distance.

If all the specimens under different conditions at a distance of $3000 \mathrm{~m}$ are compared then the wear is more in cryogenically treated specimen and the wear rate is relatively less in $350^{\circ} \mathrm{C}$ treated specimens. Similarly if the specimens at distance of $5000 \mathrm{~m}$ are compared the wear is more in normal specimens and it is less in $350^{\circ} \mathrm{C}$ treated specimens. Hence it is best to use the $350^{\circ} \mathrm{C}$ treated specimen compared to others. Wear rate of normal and cryogenic treated material is increased compared to tempered materials at $250^{\circ} \mathrm{C}$ and $350^{\circ} \mathrm{C}$ as the sliding distance increases. The wear rate for the normal, tempered $250^{\circ} \mathrm{C}$ and $350^{\circ} \mathrm{C}$ specimens increases gradually. But the wear rate depends on the hardness of the material because as hardness increases the wear rate decreases.

\subsection{Influence of Load on the Wear Behavior}

The load has a significant influence on the wear loss of the material. Figure 5 represents the variations of wear rate of the spring steel as a function of applied load for a constant sliding distance $3000 \mathrm{~m}$ and speed $700 \mathrm{rpm}$ for different material conditions like normal, $250^{\circ} \mathrm{C}, 350^{\circ} \mathrm{C}$ and cryogenic conditions. It may be noted that wear rate of spring steel metal increased with increasing load. Also as hardness increases the wear rate is reduced. The wear rate of metal is depended on the heat treated conditions of the metal and the applied load. The seizure event was accompanied by a sudden increase in wear rate, heavy noise and vibration. During this process, transfer of pin material to the disc was also observed. This type of seizure has been referred to as 
galling seizure which leads to further increase in wear rate. Wear rate of normal specimen increases gradually with applied load. The tempered $250^{\circ} \mathrm{C}$ and $350^{\circ} \mathrm{C}$ the trend appeared to be similar. But due to increase in the hardness the wear rate of $350^{\circ} \mathrm{C}$ tempered specimens is less compared to $250^{\circ} \mathrm{C}$ tempered specimens. The wear rate of cryogenic specimens increased gradually and becomes stable from 3 to $5 \mathrm{~kg}$ and again the wear rate increases suddenly.

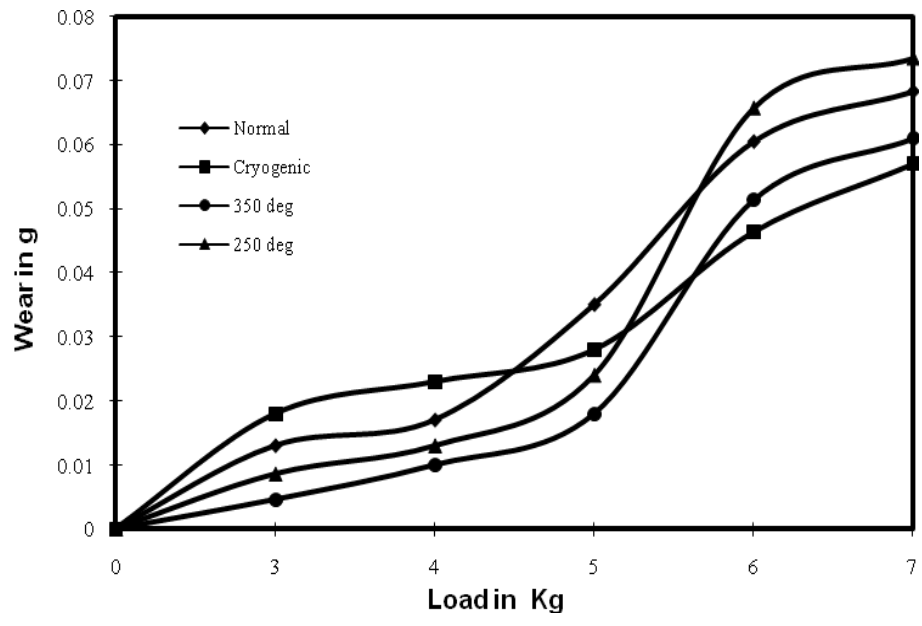

Figure 5 Shows Variations of Wear Rate of Spring Steel with Load.

It is observed from the figure 5 that as the load increases the wear also increase for all conditions because whenever applied load increases the friction at the contact surface of the material and rotating disc increases. This leads to increase in temperature and the material becomes ductile. So wear particles get adhered to the surface and leads to less wear rate. The wear rate is increased gradually up to $5 \mathrm{~kg}$ for tempered $350^{\circ} \mathrm{C}$ and $250^{\circ} \mathrm{C}$ specimens because the cracks developed due to annealing get healed up after tempering. The wear particles get adhered to the surface and layer called smeared layer is formed. Further there is sudden increase in wear rate because the smeared layer formed earlier gets peeled off. But in cryogenically conditioned specimens the cracks get widened further. The increase in temperature increases the ductility. The wear becomes stable from $3 \mathrm{~kg}$ to $5 \mathrm{~kg}$ load. Beyond $5 \mathrm{~kg}$ load the wear increases and becomes unstable. The stable condition is obtained due to the formation of smeared layer on surface of specimen which leads to reduced wear rates. This smeared layer gets peeled off leads to instability. The wear is less at $5 \mathrm{~kg}$ load for $350^{\circ} \mathrm{C}$ heat treated specimens and relatively wear is more for normal conditioned specimen and at $7 \mathrm{~kg}$ load the wear is less for cryogenically conditioned specimens and it is more for $250^{\circ} \mathrm{C}$ treated specimens. Hence it is best to use cryogenically conditioned specimens under the above context.

\subsection{Influence of Speed on the Wear Behavior}

The wear rate of the pin increases with increasing speed. As the speed increases the temperature increases which leads to plastic deformation of the material. At lower speed the pin surface 
experiences severe damage resulting in a high wear rate as shown in figure 6 . The wear rate of normal and $250^{\circ} \mathrm{C}$ material condition is increased compared to other treated conditions as the sliding speed increases.

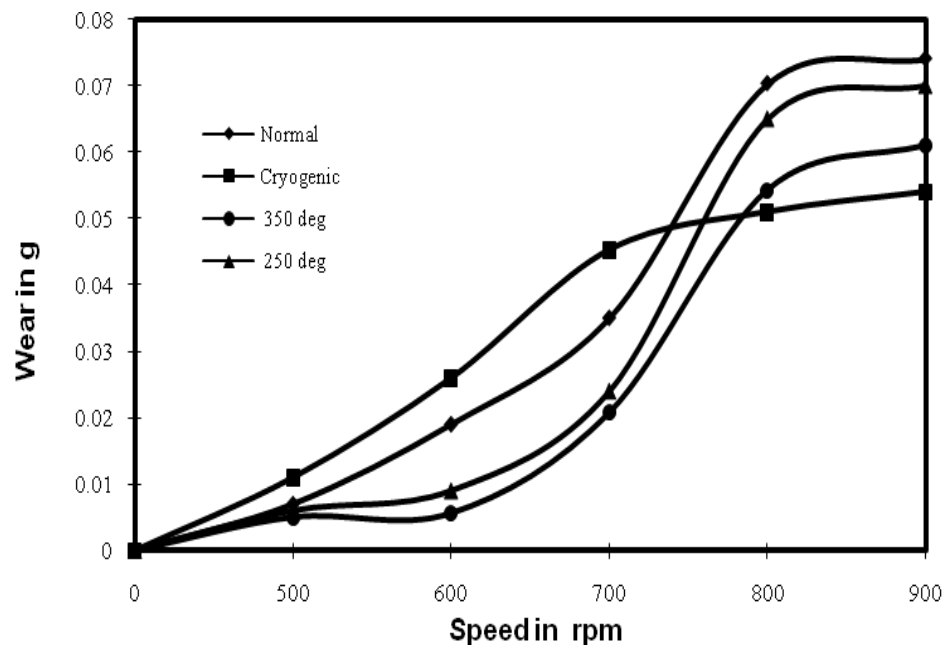

Figure 6 Shows Variations of Wear Rate of Spring Steel with Speed.

It can be noticed from Figure 6 that the wear rate increases with the increase in speed. If the normal specimen is considered the wear is increasing continuously upto $800 \mathrm{rpm}$. If the $350^{\circ} \mathrm{C}$ treated and $250^{\circ} \mathrm{C}$ treated specimens are considered wear will increase up to $500 \mathrm{rpm}$ speed beyond which it becomes stable up to $600 \mathrm{rpm}$ due to the formation of the smeared layer and the wear rate again increases continuously upto $800 \mathrm{rpm}$ because the smeared layer gets peeled off and again it becomes stable. In cryogenic treated specimen the wear is continuously increasing upto $700 \mathrm{rpm}$ after that it becomes stable because there is decrease in wear rates because of this reason the material becomes good one for further application. At $700 \mathrm{rpm}$ the wear is less for $350^{\circ} \mathrm{C}$ treated specimen and relatively the wear rate is more for cryogenically treated specimens and at $900 \mathrm{rpm}$ the wear is less for cryogenic specimen and relative wear is high for normal specimen.

From the above comparison the best one is to use the $350^{\circ} \mathrm{C}$ heat treated specimen because it can sustain the load, distance, speed and gives less wear compared to other specimens. The heat treated specimens are suitable to use because in heat treated specimens the crack gets healed on tempering but in cryogenically conditioned specimens even though the hardness is high the cracks go on widening. So for further usage the tempering should be done after cryogenic treatment which again reduces the crack density and heals the crack. From above figures 5,6,7 the $350^{\circ} \mathrm{C}$ heat treated specimen will sustain more for varying load, speed and distance as compare to other specimens because of high hardness due to tempering and the crack density so less wear will takes place. 


\subsection{Design of Experiments}

In order to reduce the number of experiments and also to determine the interaction of the individual parameters, the experimental design is made. In this $\mathrm{L}_{9}$ array is used. The experiments were carried according to the standard $\mathrm{L}_{9}$ array. The results of the experimentations are shown in the Table 5 .

Table 5 Weight Loss of Wear Specimen

\begin{tabular}{cccccc}
\hline Trial no. & $\begin{array}{c}\text { Load(P) in } \\
\mathrm{Kg}\end{array}$ & $\begin{array}{c}\text { Speed(N) in } \\
\text { rpm }\end{array}$ & $\begin{array}{c}\text { Distance(D) } \\
\text { in } \mathrm{m}\end{array}$ & Material & $\begin{array}{c}\text { Weight loss } \\
\text { in } \mathrm{g}\end{array}$ \\
\hline 1 & 7 & 900 & 5000 & $350^{\circ} \mathrm{C}$ & 0.1143 \\
2 & 7 & 700 & 3000 & $250^{\circ} \mathrm{C}$ & 0.0301 \\
3 & 7 & 500 & 1000 & $27^{\circ} \mathrm{C}$ & 0.0227 \\
4 & 5 & 900 & 3000 & $27^{0} \mathrm{C}$ & 0.0997 \\
5 & 5 & 700 & 1000 & $350^{\circ} \mathrm{C}$ & 0.0548 \\
6 & 5 & 500 & 5000 & $250^{\circ} \mathrm{C}$ & 0.0049 \\
7 & 3 & 900 & 1000 & $250^{\circ} \mathrm{C}$ & 0.0021 \\
8 & 3 & 700 & 5000 & $27^{\circ} \mathrm{C}$ & 0.0148 \\
9 & 3 & 500 & 3000 & $350^{\circ} \mathrm{C}$ & 0.0034 \\
\hline
\end{tabular}

During the initial periods of sliding the LVDT showed negative wear due to expansion (of pin, holder assembly and disc) by frictional heat. During this period wear rate showed a non-linear behavior with time followed by a steady linear positive wear. This was confirmed by allowing the whole assembly to cool down after the experiment, simultaneously recording the contraction using the LVDT. At high load $(7 \mathrm{~kg})$ it was found that wear rate was more $(0.1143)$ whereas at low load (3kg) the wear rate was less $(0.0034)$. The wear test results were subjected to the analysis of variance. Analysis of influence of each control factor on the weight loss has been performed with so called signal- to- noise $(\mathrm{S} / \mathrm{N})$ response table. The below table shows experimental layout and results of dry sliding wear test of spring steel. The $\mathrm{S} / \mathrm{N}$ ratio at each level of control factors changes when settings of each control factor are changed from L1 to L3. The control factor with a strongest influence is determined by difference in values. The higher the difference, more influential is the control factor. In view of the fact that the theory claims that applied load and hardness of materials are most important factors affecting the sliding process. For EN-47 steel however load exerted greatest effect on sliding wear which is closely 
followed by material conditions. The effect of sliding distance on the wear was less. The strongest control factors are shown in the Table 6.

Table 6 Signal to Noise Ratio of Wear Specimens

\begin{tabular}{cccccc}
\hline Trial no. & $\begin{array}{c}\text { Load(P) in } \\
\mathrm{Kg}\end{array}$ & $\begin{array}{c}\text { Speed(N) in } \\
\text { rpm }\end{array}$ & $\begin{array}{c}\text { Distance(D) } \\
\text { in } \mathrm{m}\end{array}$ & Material & $\begin{array}{c}\text { Signal to } \\
\text { Noise Ratio } \\
\text { SN }\end{array}$ \\
\hline 1 & 7 & 900 & 5000 & $350^{\circ} \mathrm{C}$ & 18.839 \\
2 & 7 & 700 & 3000 & $250^{\circ} \mathrm{C}$ & 30.428 \\
3 & 7 & 500 & 1000 & $27^{\circ} \mathrm{C}$ & 32.879 \\
4 & 5 & 900 & 3000 & $27^{\circ} \mathrm{C}$ & 20.026 \\
5 & 5 & 700 & 1000 & $350^{\circ} \mathrm{C}$ & 25.224 \\
6 & 5 & 500 & 5000 & $250^{\circ} \mathrm{C}$ & 46.196 \\
7 & 3 & 900 & 1000 & $250^{\circ} \mathrm{C}$ & 53.555 \\
8 & 3 & 700 & 5000 & $27^{\circ} \mathrm{C}$ & 36.594 \\
9 & 3 & 500 & 3000 & $350^{\circ} \mathrm{C}$ & 49.370 \\
\hline
\end{tabular}

\subsection{Analysis of Variance (ANOVA)}

The ANOVA is used to investigate which design parameters significantly affect the quality characteristics. It is accomplished by separating total variability of $\mathrm{S} / \mathrm{N}$ ratio, which is measured by sum of square deviation from total mean $\mathrm{S} / \mathrm{N}$ ratio into contributions by each of the design parameters and the errors.

Table 7 Percentage Contribution of Wear Specimens

\begin{tabular}{ccccc}
\hline Trial no. & Parameters & Sum of squares & $\begin{array}{c}\text { Degrees of } \\
\text { freedom }\end{array}$ & \% contribution \\
\hline 1 & $\mathrm{P}$ & 632.106 & 2 & 49.205 \\
2 & $\mathrm{~N}$ & 289.832 & 2 & 22.56 \\
3 & $\mathrm{D}$ & 27.101 & 2 & 2.109 \\
4 & $\mathrm{M}$ & 335.63 & 2 & 26.126 \\
\hline Total & & & 8 & 100 \\
\hline
\end{tabular}

Table 7 indicates the percentage of each factor contribution on the total variation and thus exhibiting the degree of influence on result. For EN-47 steel, the load factor $(\mathrm{P} \approx 49.205 \%)$ had a 
significant influence on the weight loss of the steel. While the material conditions $(\mathrm{P} \approx 26.126 \%)$, speed $(\mathrm{P} \approx 22.561 \%)$ and the sliding distance $(\mathrm{P} \approx 2.109 \%)$ had a slight effect. The contribution of applied load is greater which may be due to the sufficiently induced stress at contact area within the experimental conditions. The linear regression equation for the wear loss of the spring steel is shown in equation below:

$$
\mathrm{W}=-0.145+0.00125 \mathrm{P}+0.000154 \mathrm{~N}+0.000005 \mathrm{D}+0.000005 \mathrm{M} .
$$

The coefficients of applied load, sliding distance, sliding speed and material conditions are positive, which indicates that wear increases with the increase in the wear parameters. It indicates that load is the main factor on wear rate for spring steel. It is followed by material conditions and sliding speed while the sliding distance was less effective than the other parameters.

Design of experiments approach by taguchi method enabled us to analyze successfully the wear behavior of the spring steel on load, sliding distance, material conditions and sliding speed as test variables. Effect of variables that is load, sliding speed and material conditions are more pronounced on the wear of the spring steel than sliding distance. The pooled error associated was zero. Wear rate of cryogenic material is decreased as the load and speed increases compared to normal and treated conditions.

\section{CONCLUSIONS}

Based on experimental analysis carried out on the heat treated spring steel material, the following conclusions have been drawn.

- The heat treated spring steel material has maximum strength whereas the normal material is found to be very poor in strength aspects.

- Condition of materials influences on the wear rate. Tempered material is having high wear rate as compared to cryogenic specimen.

- The tempered specimens are best suitable to use because in tempered specimens the crack gets healed but in cryogenically conditioned specimens even though the hardness is high the cracks go on widening.

- For further usage the tempering should be done after cryogenic treatment which again reduces the crack density and heals the crack.

- Wear rate of spring steel material increased with increasing load, speed and distance and wear rate of material depends on the heat treated conditions of the material and the applied load, speed and distance.

- The strength influences more on hardness. Heat treated material have more hardness compared to normal material. 


\section{REFERENCES}

1. J.P. Wise, J. Spice, S.G. Davidson, W.E. Heitmann and G. Krauss, "Influence of short austenizing times on the fracture behavior of a micro alloyed automotive spring steel", scripta mater, Vol 44, Year 2001, Pp 299-304.

2. C.S. Lee, K.A. Lee, D.M. Li, S.J. Yoo, W.J. Nam, "Microstructural influence on fatigue properties of a high-strength spring steel” ,material science and engineering, Vol A241, Year 1998, Pp 30-37.

3. Sinan Fank Tubitak, Ulusal Metroloji Enstitusu, Gebze, Kocaeli, "Different heat treatment processes can be applied on the spring element of a force transducer in order to obtain good and satisfactory performance".

4. A. Ardehali Barani, D. Ponge, D. Raabe, "Refinement of grain boundary carbides in a SiCr spring steel by thermo mechanical treatment", Materials Science and Engineering, Vol A 426, Year2006, Pp 194-201.

5. D. Das, A.K. Dutta, K.K. Ray, "Influence of varied cryotreatment on the wear behavior of AISI D2 steel”, wear, Vol 266, Year 2009, Pp 297-309.

6. Paolo Baldissera, Cristiana Delprete, "Effects of deep cryogenic treatment on static mechanical properties of $18 \mathrm{NiCrMo} 5$ carburized steel", Materials \& Design, Volume 30, Issue 5, May 2009, Pages 1435-1440.

7. R. Jones, L. Molent, S. Pitt, "Crack growth of physically small cracks", Engineering, Monash International Journal of Fatigue, Vol 29, Year 2007, Pp 1658-1667

8. B. Ravi Kumar, D.K. Bhattacharya, Swapan K. Das, Sandip Ghosh Chowdhury, "Premature fatigue failure of a spring due to quench cracks", engineering failure analysis , Vol 7, Year 2000 ,Pp 377-384.

9. Won Jong Nam, Chong Soo Lee, Deok Young Ban, "Effects of alloy additions and tempering temperature on the sag resistance of $\mathrm{Si}-\mathrm{Cr}$ spring steels", Materials Science and Engineering, Vol A289, Year2000, Pp 8-17.

10. M. Molnarova, I. mamuzi , J. Bacso, , M. Fujda, P. Kodronova, T. Kuskuli, I. Pokorny, "Influence of reheating and cooling conditions on structure and mechanical properties of c-mn-si steel”, Metalurgija, Vol 47 , Year 2008, Pp 187-190.

11. Masami Wakita and Takanori Kuno and Ayamitsu Amano, Akihiko Nemoto and Katsushi Saruki and Keisuke Tanaka "Study on Predicting Formula for Torsional Fatigue Strength of Spring Steel- Effect of Environment, Notch and Hardness"

12. Y. Sahin, "Optimal testing parameters on the wear behavior of various steels", Materials and design, Vol 27, Year 2006, Pp 455-460.

13. Yoshifumi Amamoto, Hozumi Goto "Friction and wear of carbon steel near T1-transition under dry sliding”, Tribology International, Vol39, Year 2006, Pp 756-762.

14. Y. Totik, R. Sadeler, H. Altun, M. Gavgali, "The effects of induction hardening on wear properties of AISI 4140 steel in dry sliding conditions", Materials \& Design, Volume 24, Issue 1, February 2003, Pages 25-30. 
15. Mare Meyers and Krishan chawla, "Mechanical behavior of materials (Second edition)"

16. S. Basavarajappa, K.V. Arun, J. Paulo Davim, "Effect of Filler Materials on Dry Sliding Wear Behavior of Polymer Matrix Composites - A Taguchi Approach", Journal of Minerals \& Materials Characterization \& Engineering, Vol. 8, No.5, Pp 379-391, 2009

17. Ross, P.J. Taguchi Techniques for Quality Engineering, McGraw-Hill Publishing Company Ltd.: New York, 1988.

18. N.E.W. Hartley, J.K. Hirvonen ,'Wear testing under high load conditions, The effect of "anti-scuff" additions to AISI 3135, 52100 and 9310 steels introduced by ion implantation and ion beam mixing”, Nuclear Instruments and Methods, Vol 209/210, Year 1983, Pp 933-940. 